\title{
Rational Use of Antibiotics and Monitoring of Drug Interactions in Patients with Respiratory Tract Infection
}

\author{
Nahid Akbari ${ }^{1}$, Ramakrishna Prudhivii ${ }^{2, *}$, Shobha Naidu ${ }^{3}$ \\ ${ }^{1}$ Department of Pharmacy Practice, Dayananda Sagar College of Pharmacy, Bengaluru- 560078, INDIA. \\ ${ }^{2}$ Department of Pharmacy Practice, Faculty of Pharmacy, Dayananda Sagar University, Bengaluru- 560078, INDIA. \\ ${ }^{3}$ Department of Chest, Consultant Physician, Sagar Hospitals, Kumaraswamy Layout, Bengaluru- 560078, INDIA.
}

\section{Received: 11 October 2018; \\ Accepted: 26 November 2018 \\ *Correspondence to: \\ Dr. Ramakrishna Prudhivi,} Assistant Professor, Department of Pharmacy Practice, College of Pharmaceutical Sciences, Dayananda Sagar University, Bengaluru- 560078, INDIA.

Email: ramakrishna.prudhivi@gmail.com

Copyright: (C) the author(s),publisher and licensee Indian Academy of Pharmacists. This is an open-access article distributed under the terms of the Creative Commons Attribution Non-Commercial License, which permits unrestricted non-commercial use, distribution, and reproduction in any medium, provided the original work is properly cited.

\begin{abstract}
Background: A respiratory tract infection (RTI) is considered as one of the commonest public health problem dealt with in primary care. Objective: To evaluate the prescribing pattern of antibiotics, drug interactions involved and their rationality in the management of respiratory tract infection. Methods: The study was conducted in $180 \mathrm{RTI}$ patients admitted in Sagar Hospital, Bengaluru. The study was a prospective, observational study. The information collected was based on inpatient case record and documented in the predesigned patient profile form. The data was analyzed and assessed using Micromedex 2.0, Medscape and www.drugs.com. Results: A total of 180 patients were included as per inclusion and exclusion criteria, out of which $98(54.4 \%)$ were male and the mean (SD) age of the patients was 58(14.3) years. Majority of patients had hypertension $77(26.22 \%)$ as co-morbidity followed by diabetes mellitus $64(21.89 \%)$. Among 180 cases, $42(23.33 \%)$ cases were diagnosed with URTI in which $7(16.66 \%)$ patients had sinusitis, $5(11.9 \%)$ had tonsillitis, $8(19.04 \%)$ had common cold, $2(4.76 \%)$ had pharyngitis and $19(45.23 \%)$ had unspecified URTI. In study population $134(74.44 \%)$ cases were diagnosed with LRTI in which $7(5.22 \%)$ were acute bronchitis, 40(29.85\%) were bronchitis, 2(1.49\%) were broncholithiasis, 29(21.64\%) were pneumonia and 56(41.80) were unspecified LRTI. 4(2.23\%) cases were diagnosed with both URTI and LRTI. In current study a total of 322 Antibiotics were prescribed among which most commonly used is Piperacillin+ Tazobactam $88(27.32 \%)$ followed by Clarithromycin 52(16.14\%). The most offending drug in major, moderate and minor drug interactions was clarithromycin $111(79.28 \%)$, clarithromycin 65(51.58\%) and Piperacillin + Tazobactam 23(56.09\%) respectively. Conclusion: This study concluded the prudent use of antibiotics will diminish the burden of multi-drug resistance and thereby providing better patient management.
\end{abstract}

Key words: Respiratory tract infection, Prescribing pattern, Rational use of antibiotics, Drug interactions.

\section{INTRODUCTION}

A Respiratory Tract Infection (RTI) is an infection anywhere in the respiratory tract (i.e. nose, throat and lungs) and is the leading cause of morbidity and mortality in many developing countries. ${ }^{[1]}$ RTI is defined as any infectious disease of the upper and lower respiratory tract. ${ }^{[2]}$ Upper respiratory tract infection (URTI) is a common infectious disease which includes the common cold, laryngitis, pharyngitis/tonsillitis, acute rhinitis, acute rhino-sinusitis and acute otitis media. Lower respiratory tract infections (LRTIs) are the most common infectious disease which includes tracheitis, bronchitis, broncholithiasis and pneumonia.

Upper respiratory tract infections including nasopharyngitis, pharyngitis, tonsillitis and otitis media constitute $87.5 \%$ of the total episodes of respiratory infections. The vast majority of acute upper respiratory tract infections are caused by viruses. ${ }^{\left[{ }^{3]}\right.}$ Lower respiratory tract infections (LRTI) are a major cause of morbidity and mortality in children aged $<5$ years in developing countries. ${ }^{[4]}$ Infections of LRTI are responsible for $4.4 \%$ of all hospital admissions and $6 \%$ of all general practitioner consultations. ${ }^{[5]}$ There is inadequate information from India on various lower respiratory tract bacterial pathogens and their resistance patterns in hospital settings. ${ }^{[6]}$ Globally more than 1.5 million deaths annually from respiratory infections are attributable to the environment, including at least $42 \%$ of lower respiratory infections and $24 \%$ of upper respiratory infections in developing countries. ${ }^{[7]}$
Antibiotics are the substances produced by microorganisms, which selectively suppress the growth or kill other microorganisms at very low concentrations. ${ }^{[8]}$ According to the current literature, before prescribing an antibiotic for these infections, a precise diagnosis must precede; such diagnosis shall establish its bacterial origin to prevent the null clinical utility of the drug and a potential risk of increasing bacterial resistance. ${ }^{[9]}$ Inappropriate use of antibiotics, particularly for RTIs, has contributed to the major public health problem of antibiotic resistance in the community. ${ }^{[10]}$ Antibiotic resistance is a global health problem and a major cause for concern. It is associated with the inappropriate, as well as frequent, use of antibiotics. ${ }^{[1]}$ Antibiotics experienced some adverse reactions to the drugs of which $20 \%$ required treatment. ${ }^{[12]}$

The prescribing pattern deals with monitoring, evaluating and suggesting modifications in the prescribing pattern, so as to make patient care safe, effective and cost effective. ${ }^{[13]}$ The identification of antibiotic-prescribing practices should be the first part of a strategy that would reduce its unnecessary usage and consequences. ${ }^{[14]}$ Irrational prescribing pattern has been widely reported from both developed as well as developing countries. ${ }^{[15]}$

A drug interaction occurs when a patient's response to a drug is modified by food, nutritional supplements, formulation excipients, environmental factors, other drugs or disease Interactions between drugs (drug-drug interactions) 
may be beneficial or harmful. Harmful drug-drug interactions are important as they cause $10-20 \%$ of the adverse drug reactions requiring hospitalization and they can be avoided. Knowing how drug-drug interactions occur and how to manage them is an important part of clinical practice. ${ }^{[16,17]}$ However, clinicians should recognize that patient satisfaction is not compromised by the absence of an antibiotic prescription provided that patients understand the reasons. ${ }^{[18]}$

Here, we explore the prescribing pattern of antibiotics in the management of respiratory tract infection and assessment of the drug interactions associated with antibiotics used in respiratory tract infections.

\section{METHODOLOGY}

Study design and settings: This was a prospective, observational study of RTI patients registered in Medicine Department at Sagar Hospitals, Bengaluru, India from September 2016 to February 2017(six months). Ethics approval and consent to participate: All participants gave written informed consent to participate. Permission to conduct the study was obtained from Institutional ethics committee, Dayananda Sagar College of Pharmacy, Bengaluru. Sources of data: The sources of data used for this study includes, personnel interviews of patients and their representatives and patient's treatment files. Inclusion criteria: All patients either sex who diagnosed with respiratory tract infection, patients prescribed with antibiotics. Exclusion criteria: Patients who were not willing to participate in the study, patients having tuberculosis and other infections, patients suffering with other than RTI's and Immuno-supressed patients. Study procedure: RTI patients visiting medicine department were identified and consented. Patients were enrolled in the study based on inclusion and exclusion criteria. Informed consent was obtained from the patient at the time of enrollment. During the study, the inpatient case records were reviewed which included patient demographics, antimicrobials use such as names of antimicrobials, their dosage schedule, route of administration, date of discontinuation, generic name and bacteriological investigation. Antibiotics were subsequently categorized into classes, informed by British National Formulary subcategories. ${ }^{[19]}$ The information collected was documented in the predesigned patient profile form. The rationality of antibiotics was analyzed with the help of guidelines prepared from Micromedex and ACP. The dose, indication, route and duration of antibiotics were verified from Micromedex. The drug interactions were assessed using Micromedex 2.0, Medscape and www.drugs. com. Statistical analysis: Categorical variables were reported as frequency and percentage frequency. Chi square test was performed to determine the strength of association between gender and variables P-value less than 0.05 were considered as statistically significant. Data was analyzed using a statistical tool Graph Pad Prism software version 5.0.

\section{RESULTS}

Patient characteristics: A total of 180 patients were included as per inclusion and exclusion criteria, out of which $98(54.4 \%)$ were male and $82(45.6 \%)$ were female. The mean (SD) age of the patients was 58(14.3) years. The majority $95(52.77 \%)$ of the patients belonged to age group $>60$ years. $163(90.55 \%)$ patients were married. There were $124(68.89 \%)$ cases of nonsmokers where 22(12.21\%) were occasional smoker, 11(6.11\%) were ex-smoker and $23(12.79 \%)$ were smokers. Out of 180 patients, $4(2.22 \%)$ patients were having alcohol consumption in which $51(28.34 \%)$ were occasional alcoholic, 9(5\%) were ex-alcoholic and 116(64.44\%) were nonalcoholic patients (Table 1). Table 2 showed analysis of socio-demographic characteristic of patients. There is a significant difference between male and female in smoking habit and alcohol consumption.

\begin{tabular}{|c|c|}
\hline VARIABLES & N (\%) \\
\hline GENDER & $98(54.4)$ \\
\hline Male & $82(45.6)$ \\
\hline \multicolumn{2}{|l|}{ Female } \\
\hline \multicolumn{2}{|l|}{ AGE (YEARS) } \\
\hline $0-10$ & $5(2.77)$ \\
\hline $11-20$ & $3(1.66)$ \\
\hline $21-30$ & $17(9.44)$ \\
\hline $31-40$ & $18(10)$ \\
\hline $41-50$ & $11(6.11)$ \\
\hline $51-60$ & $31(17.22)$ \\
\hline$>60$ & $95(52.77)$ \\
\hline \multicolumn{2}{|l|}{ MARITAL STATUS } \\
\hline Married & 163(90.55) \\
\hline Unmarried & $17(9.44)$ \\
\hline \multicolumn{2}{|l|}{ SMOKING } \\
\hline Non Smoker & 124(68.89) \\
\hline Ex-smoker & $11(6.11)$ \\
\hline Occasional smoker & $22(12.21)$ \\
\hline smoker & $23(12.79)$ \\
\hline \multicolumn{2}{|l|}{ ALCOHOL } \\
\hline Non alcoholic & $116(64.44)$ \\
\hline Ex-alcoholic & $9(5)$ \\
\hline Occasional alcoholic & $51(28.34)$ \\
\hline Alcoholic & $4(2.22)$ \\
\hline
\end{tabular}

\begin{tabular}{|c|c|c|c|c|c|}
\hline \multicolumn{2}{|c|}{ VARIABLE } & \multirow{2}{*}{$\begin{array}{l}\text { MALE } \\
98(54.4 \%) \\
53(52.47)\end{array}$} & \multirow{2}{*}{$\begin{array}{l}\text { FEMALE } \\
82(45.5 \%) \\
48(47.53)\end{array}$} & \multirow{3}{*}{$\begin{array}{l}\text { CHI - } \\
\text { SQUARE } \\
\text { VALUE }\end{array}$} & \multirow{3}{*}{$\begin{array}{l}\boldsymbol{P} \\
\text {-VALUE } \\
0.5486\end{array}$} \\
\hline \multirow{2}{*}{ Age } & $\leq 65$ & & & & \\
\hline & $>65$ & $45(56.96)$ & $34(43.04)$ & & \\
\hline \multirow{2}{*}{$\begin{array}{l}\text { Marital } \\
\text { status }\end{array}$} & Married & $87(53.37)$ & $76(46.63)$ & \multirow{2}{*}{$\begin{array}{l}1.832, \\
d f=1\end{array}$} & \multirow{2}{*}{0.1758} \\
\hline & Unmarried & $12(70.58)$ & $5(29.41)$ & & \\
\hline \multirow{4}{*}{$\begin{array}{l}\text { Smoking } \\
\text { status }\end{array}$} & Non Smoker & $44(35.48)$ & $80(64.51)$ & \multirow{4}{*}{$\begin{array}{l}58, \\
d f=3\end{array}$} & \multirow{4}{*}{$<0.0001$} \\
\hline & Ex-smoker & 10(90.9) & $1(9.09)$ & & \\
\hline & $\begin{array}{l}\text { Occasional } \\
\text { smoker }\end{array}$ & 21(95.45) & $1(4.54)$ & & \\
\hline & Smoker & $23(100)$ & 0 & & \\
\hline \multirow{4}{*}{$\begin{array}{l}\text { Alcohol } \\
\text { status }\end{array}$} & $\begin{array}{l}\text { Non } \\
\text { alcoholic }\end{array}$ & $47(28.31)$ & $69(59.49)$ & \multirow{4}{*}{$\begin{array}{l}53, \\
d f=3\end{array}$} & \multirow{4}{*}{$<0.0001$} \\
\hline & Ex-alcoholic & $9(100)$ & 0 & & \\
\hline & $\begin{array}{l}\text { Occasional } \\
\text { alcoholic }\end{array}$ & $38(74.5)$ & $13(25.5)$ & & \\
\hline & alcoholic & $4(100)$ & 0 & & \\
\hline
\end{tabular}

Values are significant If $\mathrm{P}$-value $<0.05$ 


\begin{tabular}{|c|c|c|}
\hline CO-MORBIDITY & NO. OF CASES & PERCENTAGE \\
\hline Hypertension & 77 & 26.22 \\
\hline Diabetes mellitus & 64 & 21.89 \\
\hline Asthma & 33 & 11.36 \\
\hline IHD & 29 & 9.86 \\
\hline Hypothyroidism & 22 & 7.48 \\
\hline Kidney diasease & 21 & 7.14 \\
\hline COPD & 11 & 3.74 \\
\hline UTI & 7 & 2.38 \\
\hline Anemia & 6 & 2.04 \\
\hline Hyperlipidemia & 5 & 1.70 \\
\hline Seizure & 5 & 1.70 \\
\hline Methabolic acidosis & 3 & 1.02 \\
\hline Sepsis & 3 & 1.02 \\
\hline Dehydration & 2 & 0.68 \\
\hline Obesity & 2 & 0.68 \\
\hline Parkinsonism & 2 & 0.68 \\
\hline Gout & 1 & 0.34 \\
\hline Hypoglycemia & 1 & 0.34 \\
\hline
\end{tabular}

\begin{tabular}{|l|l|l|}
\hline \multicolumn{3}{|l|}{ Table 4: Classification of respiratory tract infections. } \\
\hline TYPE OF RTI & NO. OF PATIENTS & PERCENTAGE \\
\hline URTI & $\mathbf{4 2}$ & $\mathbf{2 3 . 3 3}$ \\
\hline Sinusitis & 7 & 16.66 \\
\hline Tonsillitis & 5 & 11.9 \\
\hline Common cold & 8 & 19.04 \\
\hline Pharyngitis & 2 & 4.76 \\
\hline Unspecified & 19 & 45.23 \\
\hline LRTI & $\mathbf{1 3 4}$ & $\mathbf{7 4 . 4 4}$ \\
\hline Acute bronchitis & 7 & 5.22 \\
\hline Chronic bronchitis & 40 & 29.85 \\
\hline Broncholithiasis, & 2 & 1.49 \\
\hline Pneumonia & 29 & 21.64 \\
\hline Unspecified & 56 & 41.80 \\
\hline BOTH & $\mathbf{4}$ & $\mathbf{2 . 2 3}$ \\
\hline
\end{tabular}

Co-morbidities: Majority of patients had hypertension $77(26.22 \%)$ as co-morbidity followed by diabetes mellitus $64(21.89 \%)$. Highest number of co-morbidities seen in one patient was found to be four (Table 3).

Culture sensitivity test and TLC: In this study 130(72.22\%) patients were undergone culture sensitivity test. Other diagnostic test like TLC was also performed. All patients were undergone TLC test and most of the patients 131(72.78\%) had total leukocyte count more than 10000 cells $/ \mathrm{cmm}$.

Classification of RTI: Among 180 cases, 42(23.33\%) cases were diagnosed with URTI in which $7(16.66 \%)$ patients had sinusitis, $5(11.90 \%)$ had tonsillitis, $8(19.04 \%)$ had common cold, $2(4.76 \%)$ had pharyngitis and $20(47.64 \%)$ had unspecified URTI. In study population $134(74.45 \%)$ cases were diagnosed with LRTI in which $7(5.22 \%)$ were acute bronchitis, $40(29.85 \%)$ were bronchitis, $2(1.49 \%)$ were broncholithiasis, $29(21.64 \%)$ were pneumonia and 56(41.80) were unspecified LRTI. 4(2.23\%) cases were diagnosed with both URTI and LRTI (Table 4).
Hospital Duration: The maximum number of patients $16.11 \%$ stayed in the hospital for duration of 5 days and the mean average stay of hospitalization were found to be $6.4 \pm 3.22$ days.

Major antibiotics prescribed: Among our 180 patients the maximum number of drugs prescribed was 20 drugs per prescription and least was 2 drugs per prescription. In the current study a total of 322 Antibiotics were prescribed among which most commonly used is Piperacillin+ Tazobactam 88(27.32\%) followed by Clarithromycin 52(16.14\%) (Figure 1).

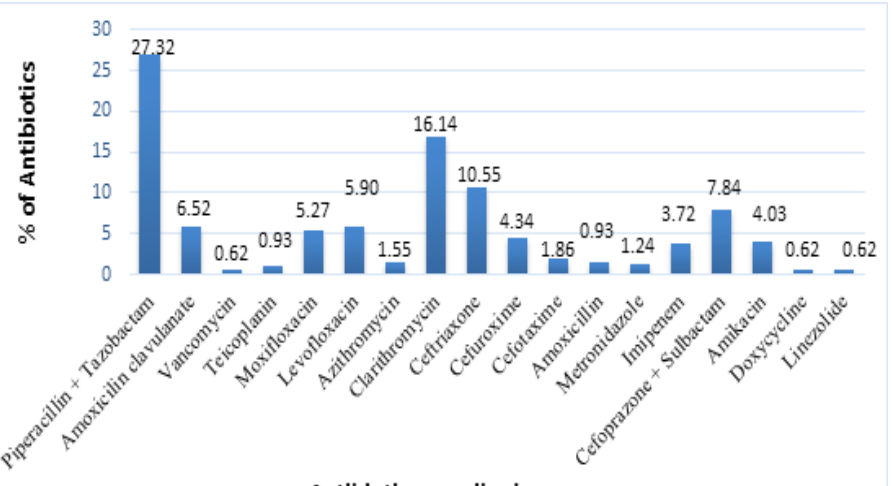

Antibiotic prescribed

Figure 1: Distribution of antibiotics used in RTI treatment.

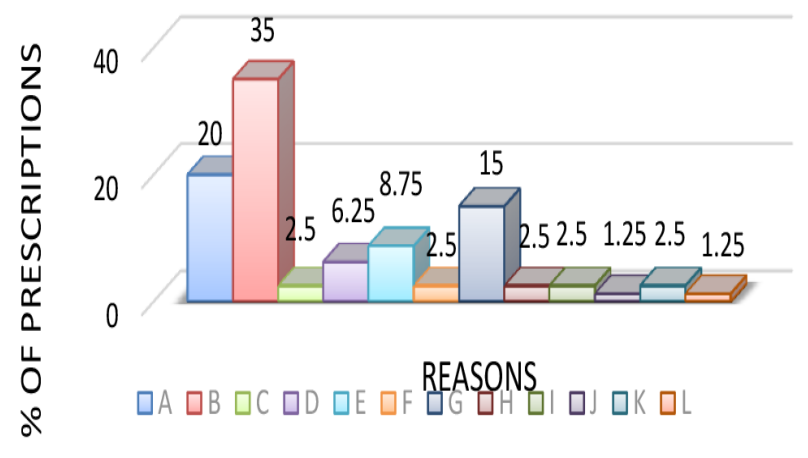

Figure 2: Reasons for irrational use of antibiotics.

$A=$ Inappropriate duration of treatment

$\mathrm{B}=$ Culture sensitivity test not advised

$\mathrm{C}=$ Inappropriate selection of Antibiotics for continue in discharge medication chart.

$\mathrm{D}=$ Dose adjustment for kidney failure didn't consider

$E=$ Dose adjustment for elderly didn't consider

$\mathrm{F}=$ Inappropriate duration of treatment and not dose adjustment for kidney failure

G= Inappropriate duration of treatment and culture sensitivity test didn't advised

$\mathrm{H}=$ Culture sensitivity test didn't advised and dose adjustment for kidney failure patients didn't consider

I= Dose adjustment for elderly didn't consider and dose adjustment for kidney failure patients didn't consider

$\mathrm{J}=$ Inappropriate duration of treatment and not dose adjustment for elderly

$\mathrm{K}=$ Culture sensitivity test didn't advised and not dose adjustment for children

$\mathrm{L}=$ Culture sensitivity test didn't advised and dose adjustment for elderly didn't consider 


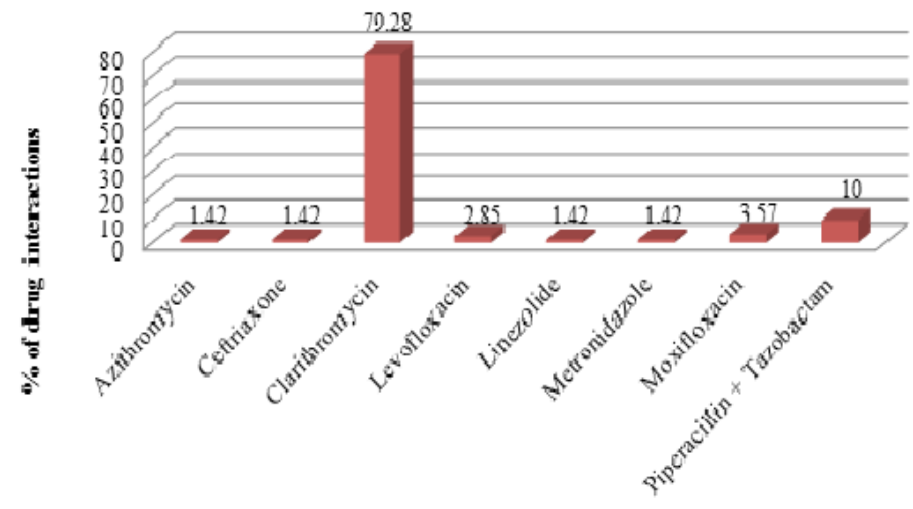

Antibiotics

Figure 3: Distribution of antibiotics with major drug interactions.

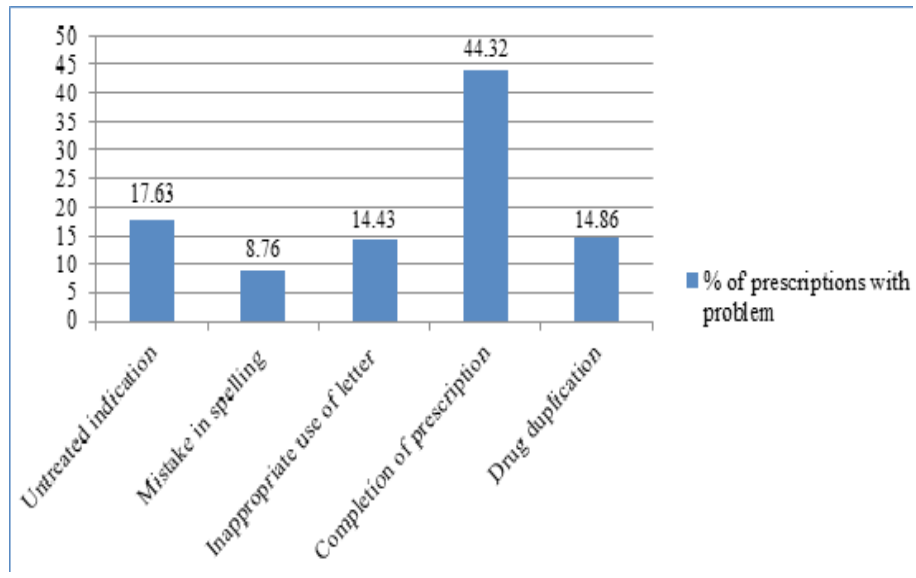

Figure 4: Distribution of problems identified in prescriptions.

Rationality: It was found that $55.55 \%$ of prescriptions were rationally prescribed and $44.45 \%$ were irrational prescription of antibiotics out of which maximum number $28(35 \%)$ was for this reason that culture sensitivity test was not advised which lead to inappropriate choice of antibiotics (Figure 2).

Drug interactions: Out of 180 prescriptions, 129(71.67\%) were found to have possible drug interactions among which $45.60 \%$ were major, $41.04 \%$ were moderate, $13.36 \%$ were minor drug interactions. The most offending drug in major, moderate and minor were clarithromycin 111(79.28\%) (Figure 3), clarithromycin 65(51.58\%) and Piperacillin + Tazobactam $23(56.09 \%)$ respectively.

Problems identified: As shown in Figure 4 there were some cases of problems occurred in prescriptions which included duplication (14.86\%), Untreated indication (17.63\%), Spelling of drug $(8.76 \%)$, inappropriate use of letter in prescription (capital/small) (14.43\%), completion of prescription (dose, frequency, route of administrations) $(44.32 \%)$.

\section{DISCUSSION}

The present study includes a total of 180 patients, as per the inclusion and exclusion criteria and there were 54.4\% males and $45.6 \%$ females which was found to be similar as study conducted by Divia et al. and concluded that there was no much variation between males and females. ${ }^{[20]}$ As per the study population the greatest number of patients was in the age group of above 60 years with the mean (SD) age of 58(14.3). This was similar to the study conducted by Rosman et al. where it was found that greatest number of patients were in the age group of more than 60 years with the mean age of $56.2 \pm 17.7$ years. ${ }^{[2]}$ Majority of patients were nonsmokers and non-alcoholics which was similar to study. ${ }^{[23]}$

Among 180 patients studied, there were a total of 294 co-existing illness such as HTN $26.22 \%$, DM $21.89 \%$, Asthma $11.36 \%$ which was similar to Harish et al., study where it found that HTN 38.2\%, DM 36.2\%, Asthma $13.3 \%$. ${ }^{[24]}$

In this study $72.22 \%$ patients were undergone culture sensitivity test which helps in providing accurate antibiotic therapy. Other diagnostic test like TLC was also performed for all patients. In a study done by Harish GN et al. showed that culture sensitivity was done in $33.33 \%$. The decrease in the percentage of culture might be based on the clinical presentation at the time of admission or patient might have consumed the antibiotic prior to admission. ${ }^{[24]}$

In current study patients were categorized based on the type of RTI such as LRTI and URTI. Among 180 patients $75.45 \%$ of them were diagnosed with LRTI which was further categorized as acute bronchitis $5.22 \%$, chronic bronchitis $29.85 \%$, broncholithiasis $1.49 \%$, pneumonia $21.64 \%$, unspecified $41.80 \%$, In a study carried out by Divya et al. out of 67 patients $46.55 \%$ were acute bronchitis $27.58 \%$ were pneumonia $20.68 \%$ were bronchopneumonia, $3.44 \%$ patients had COPD and $1.72 \%$ was chronic bronchitis. ${ }^{[20]}$

In this study $23.33 \%$ of the cases were diagnosed with URTI. Out of which $19.04 \%$ had common cold, $4.76 \%$ had pharyngitis, $16.66 \%$ patients had sinusitis, $11.90 \%$ had tonsillitis and $47.64 \%$ had unspecified URTI. In another study conducted by Harish et al. diagnosis of URTI accounted for nonspecific URTI $56.5 \%$, sinusitis $28 \%$, pharyngitis $12 \%$ and CSOM $3.5 \%{ }^{[21]}$

In present study the maximum number of patients $16.11 \%$ stayed in the hospital for duration of 5 days and the mean average stay of hospitalization was found to be $6.4 \pm 3.22$ days which was similar to the study conducted by Rosman et al. where the mean average stay of hospitalization was found to be $6.9 \pm 5.33$ days. ${ }^{[22]}$

An audit of antibiotic prescribing patterns is an important indicator of the quality and standard of clinical practice. The most commonly prescribed antibiotics according their classes were combination of Penicillin + Beta lactamase inhibitors $33.84 \%$ followed by Cephalosporins $16.75 \%$. In other study conducted by Rajalingam $\mathrm{R}$ et al. the most commonly prescribed antibiotics were Cephalosporins 15.38\%, followed by Quinolones 6.76\%. [25] The study of prescribing patterns is a part of medical audit and seeks to monitor, evaluate and if necessary, suggest modification in prescribing practice to make medical care rational.

When rationality was checked for overall appropriateness of antibiotics prescribed were analyzed and it was found to be $55.55 \%$. In a study conducted by Rajalingam et al. the assessment of rationality was performed by collecting evidences from published literature about individual antibiotics. The results showed that rationality was found to be $57.85 \%$. $^{[25]}$

In the current study prescriptions were subjected to drug interactions. The results revealed that out of 180 prescriptions, $71.67 \%$ were found to have drug interactions. The results of drug interactions between drugs prescribed with antibiotics was found to have 307 drug interactions, among which $45.60 \%$ were major, $41.04 \%$ were moderate, $13.36 \%$ were minor drug interactions. The most offending drug in major, moderate and minor was clarithromycin $79.28 \%$, clarithromycin $51.58 \%$ and Piperacillin + Tazobactam 
$56.09 \%$ respectively. In study conducted by Divia et al. revealed that $67.5 \%$ prescriptions had at least 1 interaction and remaining 32.5\% did not have any drug interactions at all. The number of drug interactions from these 135 prescriptions was counted to be 148 . Out of 200 prescriptions, $25.42 \%$ of interactions were caused by antibiotics. Incidence of drug interactions was major $31.75 \%$, moderate $42.56 \%$ and minor $25.67 \%$. ${ }^{[20]}$

Prevention of medication errors is a priority for health services. Pharmacists routinely screen prescriptions for potential problems, including prescribing errors. This study identified presence of some of problems with prescriptions of our population of study. In the analysis of prescriptions, the results showed there were some cases of problems occurred in prescriptions which included duplication, Untreated indication, Spelling of drug, Inappropriate use of letter in prescription (capital/small), Completion of prescription (dose, frequency, route of administrations). Out of 180 prescriptions, $14.86 \%$ prescriptions were found to have drug duplications. The most common drug duplication was with injection or tablet Lasix (Furosemide) with tablet Lasilactone (Furosemide+ Spironolactone) and nebulizer Asthalin (Salbutamol) with nebulizer Duolin (Salbutamol+ Ipratropium). Other problems identified include untreated indications $17.63 \%$, spelling of drug $8.76 \%$, inappropriate use of letter in prescription (capital/small) $14.43 \%$, Completion of prescription $44.32 \%$ (dose $59.30 \%$, frequency $27.91 \%$ and route of administrations $12.79 \%$ ). No literature was available to compare the variables for the present study.

\section{CONCLUSION}

This study concluded the prudent use of antibiotics which will diminish the burden of multi-drug resistance and thereby providing better patient management and limiting the outcome morbidity and mortality arising from respiratory tract infections. There is essential need for microbiological investigation before treatment of infections. The result of this study distinctly illustrated the majority of antibiotics were not complying with the WHO and ACP guidelines used for the assessment of rationality.

Most potential drug interactions can be detected by applying principles of clinical pharmacology and good clinical care. Increased awareness by clinicians at the time of choosing of drug decreases the unwanted drug interactions before they cause significant harm. The addition of clinical pharmacist services in the care of in patients with respiratory tract infections resulted in better care team, assessing rational use of drug, detecting possible drug interaction, interacting with physicians which leads to improved outcomes.

\section{ACKNOWLEDGEMENT}

Authors are thankful to the head of Sagar Hospital, Bengaluru, India and staff members of Medicine department for providing support and facilitating the data collection.

\section{CONFLICT OF INTEREST}

The authors declare no conflict of interest

\section{REFERENCES}

1. Malladi P, Hasna AH, Ramesh S, Manna PK. Role of clinical pharmacist in promoting rational use of antimicrobial in the management of pediatric lower respiratory tract infection in a tertiary teaching hospital. Int J Res Pharm Chem. 2012;2(2):360-70.

2. Tan $T$, Little $P$, Stokes $T$. Antibiotic prescribing for self-limiting respiratory tract infections in primary care: summary of NICE guidance. British Med J. 2008;337(23):231-4.

3. Jain N, Lodha R, Kabra SK. Upper respiratory tract infections. Indian J Pediatrics. 2001;68(12):1135-8.
4. Leowski J. Mortality from acute respiratory infections in children under 5 years of age: global estimates. World Health Status Quart. 1986;39(2):138-44.

5. Anderson H, Esmail A, Hollowell J, Littlejohns P, Strachen D. Epidemeologically based needs assessment: Lower respiratory diseases. DHA Project Research Programme. 1993;6-12.

6. Khan IA, Subramanyam G. Efficacy and safety of azithromycin with various cephalosporins used in treatment of lower respiratory tract infection. Indian J Pharm Pract. 2009;2(1):53-61.

7. The Global Impact of Respiratory Disease, Available from: http://www.who.int/gard/ publications/The_Global_Impact_of_Respiratory_Disease.pdf.

8. Tripathi KD. Essentials of medical pharmacology, $7^{\text {th }}$ ed. New Delhi: Jaypee brothers Medical Publishers; 1985;627-9.

9. Pérez-Cuevas R, Guiscafré H, Muñoz O, Reyes H, Tomé P, Libreros V, et al. Improving physician prescribing patterns to treat rhinopharyngitis, Intervention strategies in two health systems of Mexico. Social Sci Med J. 1996;42(8):1185-94.

10. Gjelstad S, Dalen I, Lindbæk M. GPs' antibiotic prescription patterns for respiratory tract infections-still room for improvement. Scandinavian J Primary Health Care. 2009;27(4):208-15.

11. Arnold SR, Straus SE. Improving how antibiotics are prescribed by physicians working in the community. Cochrane Summaries. 2009. c2012. Available from: http://summaries. cochrane.org/CD003539/improving-how-antibiotics-are-prescribed-byphysiciansworking-in-the-community.

12. Akter SF, Rani MF, Rahman JA, Nordin MS, Satwi S, Awang MB. Antimicrobial use and factors influencing prescribing in medical wards of a tertiary care hospital in Malaysia. International Journal of science, Environment and Technology. 2012;1(4):274-84.

13. Remesh A, Salim S, Gayathri AM, Nair U, Retnavally KG. Antibiotics prescribing pattern in the in-patient department of a tertiary care hospital. Arch Pharma Practice. 2013;4(2):71-6.

14. Osnaya-Romero N, de Jesus MT, Flores-Hernández SS, León-Rojas G. Clinical symptoms observed in children envenomated by scorpion stings, at the children's hospital from the State of Morelos, Mexico. Toxicon Journal. 2001;39(6):781-785.

15. Kumar J, Shaik MM, Kathi MC, Deka A, Gambhir SS. Prescribing indicators and pattern of use of antibiotics among medical outpatients in a teaching hospital of Central Nepal. J College Med Sci-Nepal. 2010;6(2):7-13.

16. Pirmohamed M, James S, Meakin S, Green C, Scott AK, Walley TJ, et al. Adverse drug reactions as cause of admission to hospital: prospective analysis of 18820 patients. British Med J. 2004;329(7456):15-9.

17. Merlo J, Liedholm H, Lindblad U, Björck-Linné A, Fält J, Lindberg G, et al. Prescriptions with potential drug interactions dispensed at Swedish pharmacies in January 1999: cross sectional study. British Med J. 2001;323(7310):427-8.

18. Hamm RM, Hicks RJ, Bemben D. Antibiotics and respiratory infections: Antibiotics and respiratory infections: are patients more satisfied when expectations are met?. J Family Pract. 1996;43(1):56-62.

19. Kendall M. Joint formulary committee, British national formulary. Clinical Med J. 2009;9(4):349-52.

20. Divya K, Satya SMV, Gayathri DHJ, Seema S. A study on prescribing pattern of antibiotics in respiratory tract infections in a tertiary care center. Int J Recent Scientific Res. 2015;6(6):4558-63.

21. Harish GN, Chitra C, Ashwini K, Rohit D, Sunil G. Drug Utilization Study on Antibiotics Use in the Upper Respiratory Tract Infection. Int $\mathrm{J}$ Recent Trends in Sci Tech. 2014;10(2):299-302.

22. Rosman S, Villiant ML, Clerc P, Vaherji R, Fleury NP. Prescribing patterns for upper respiratory tract infection in general practice in France and Netherlands. European $\mathrm{J}$ Public Health. 2007;1(5):25-32.

23. Nuorti JP, Butler JC, Farley MM, Harrison LH, McGeer A, Kolczak MS, Breiman RF. Cigarette smoking and invasive pneumococcal disease. Active Bacterial Core Surveillance Team. New England J Med. 2000;342(10):681-9.

24. Harish GN, Chitra C, Ashwini K, Rohit D, Sunil G. Drug utilization study on antibiotics use in lower respiratory tract infection. Nat J Med Res. 2013;3(4):324-7.

25. Rajalingam B, Achsah SA, Adreen G, Chinnu C, Cliny C. Assessment of rational use of antibiotics in a private tertiary care teaching hospital. Indian $\mathrm{J}$ Pharm Pract. 2016;9(1):234-6.

Cite this article as: Akbari N, Prudhivi R, Naidu S. Rational Use of Antibiotics and Monitoring of Drug Interactions in Patients with Respiratory Tract Infection. J Pharm Pract Community Med. 2018;4(4):211-5. 